\title{
Synthesis and characterization of spiro(adamantane-2,9'-fluorene)-based triaryldiamines: thermally stable hole-transporting materials
}

\author{
Ching-Hsin Chen, Wen-Jian Shen, Kavitha Jakka, Ching-Fong Shu* \\ Department of Applied Chemistry, National Chiao Tung University, Hsin-Chu 30035, Taiwan
}

Received 10 November 2003; received in revised form 4 December 2003; accepted 4 December 2003

\begin{abstract}
New triaryldiamines, Adm-TPD and Adm-NPD, which contain a spiro(adamantane- $2,9^{\prime}$-fluorene) core, have been synthesized and characterized. We believe that because of the presence of the rigid spiro-fluorene core, these triaryldiamines exhibit higher glass transition temperatures and have a less tendency to crystallize relative to their biphenyl analogs. Additionally, electrochemical studies showed that the planarity of the fluorene core leads to lower ionization potentials and greater degrees of $\pi$ conjugation between the two amino groups. AFM measurements demonstrated that high-quality amorphous films of Adm-NPD with good morphological stability were prepared by vapor deposition. Electroluminescent devices using Adm-NPD as a hole-transporting layer-i.e., having the configuration ITO/Adm-NPD/Alq $3 / \mathrm{LiF} / \mathrm{Al}$ - emit a bright green light that is characteristic of $\mathrm{Alq}_{3}$.
\end{abstract}

(C) 2003 Elsevier B.V. All rights reserved.

Keywords: Adamantane; Fluorene; Triaryldiamine; Hole-transporting material; OLED

\section{Introduction}

Since the discovery of multi-layered organic light-emitting diodes (OLEDs) by Tang and Van Slyke [1] electroluminescent devices have been the subject of intensive investigations because they have applications in full-color displays [2-6]. In addition to attempts at improving device efficiency, many studies have focused on enhancing the durability of OLEDs. Thermal stress can cause amorphous organic films to crystallize, forming polycrystalline films, which leads to device failure [7-9]. A considerable amount of evidence indicates that an amorphous thin film (in OLEDs) with a high glass transition temperature $\left(T_{\mathrm{g}}\right)$ is less vulnerable to heat damage and, hence, the corresponding device's performance is more stable [10-17]. Thus, high $T_{\mathrm{g}}$ materials are always desirable in OLED applications.

Because of their capability to form good-quality amorphous solid films, various triarylamine derivatives have been utilized as hole-transporting materials (HTM) $[5,6,17]$. Recently, many efforts have been devoted to the development of new amorphous triarylamines possessing high morphologic stability [12-14,18-25]. It has been demonstrated that the presence of a rigid fluorene (or derivatized fluorene) core, rather than a biphenyl group, leads to triarylamines

\footnotetext{
* Corresponding author. Tel.: +886-3-5712121; fax: +886-3-5723744 E-mail address: shu@cc.nctu.edu.tw (C.-F. Shu).
}

with enhanced thermal stability [12,22-25]. Herein, we report the synthesis and characterization of spiro(adamantane$2,9^{\prime}$-fluorene) derivatives with analogous diamine structures to the well-known biphenyl HTMs, TPD $\left(N, N^{\prime}\right.$-diphenyl$N, N^{\prime}$-bis(3-methylphenyl)-1, $1^{\prime}$-diphenyl-4,4'-diamine) and NPD $\quad\left(N, N^{\prime}\right.$-diphenyl- $N, N^{\prime}$-bis(1-naphthyl)-1,1'-diphenyl$4,4^{\prime}$-diamine). Because of its rigid and near-spherical structure, adamantane has been incorporated into both polymers and small molecules to provide unusual physical and thermal properties [26-30]. We expected that incorporating the spiro(adamantane-fluorene) group in these hole-transporting materials would increase their glass transition temperatures $\left(T_{\mathrm{g}}\right)$, thermal stabilities, and molecular rigidities, as well as to reduce their crystallinity.

\section{Experimental}

\subsection{General directions}

The solvents were dried using standard procedures. All other reagents were used as-received from commercial sources, unless otherwise stated. ${ }^{1} \mathrm{H}$ and ${ }^{13} \mathrm{C}$ NMR spectra were recorded on a Varian Unity $300 \mathrm{MHz}$ and a BrukerDRX $300 \mathrm{MHz}$ spectrometer. Mass spectra were obtained on a JEOL JMS-SX 102A mass spectrometer. Differential scanning calorimetry (DSC) was performed on a SEIKO 
EXSTAR 6000DSC unit using a heating rate of $10^{\circ} \mathrm{C} \mathrm{min}^{-1}$ and a cooling rate of $40^{\circ} \mathrm{C} \mathrm{min}^{-1}$. Samples were scanned from 30 to $300^{\circ} \mathrm{C}$, cooled to $0^{\circ} \mathrm{C}$, and then scanned again from 30 to $300^{\circ} \mathrm{C}$. The glass transition temperatures $\left(T_{\mathrm{g}}\right)$ were determined from the second heating scan. Thermogravimetric analysis (TGA) was undertaken on a DuPont TGA 2950 instrument. The thermal stability of the samples was determined under a nitrogen atmosphere, by measuring weight loss while heating at a rate of $20^{\circ} \mathrm{C} \mathrm{min}^{-1}$. UV-visible spectra were measured with an HP 8453 diode-array spectrophotometer. Photoluminescence (PL) spectra were obtained on a Hitachi F-4500 luminescence spectrometer. Cyclic voltammetry (CV) measurements were performed on a BAS $100 \mathrm{~B} / \mathrm{W}$ electrochemical analyzer with anhydrous $\mathrm{CH}_{2} \mathrm{Cl}_{2}$ containing $0.1 \mathrm{M}$ tetrabutylammonium hexafluorophosphate $\left(\mathrm{TBAPF}_{6}\right)$ as the supporting electrolyte. The potentials were measured against an $\mathrm{Ag} / \mathrm{Ag}^{+}\left(0.01 \mathrm{M} \mathrm{AgNO}_{3}\right)$ reference electrode. The onset potentials were determined from the intersection of two tangents drawn at the rising current and background current of the cyclic voltammogram. Organic EL devices were fabricated under a base vacuum of $1.3 \times 10^{-4} \mathrm{~Pa}$ in a thin-film evaporation coater and characterized following a published protocol [31]. AFM images were recorded with a Digital Instruments Nanoscope E scanning probe microscope.

\subsection{2-(2-Biphenyl)adamantanol (1)}

$n$-BuLi (2.5 M in hexane, $2.24 \mathrm{ml}, 5.60 \mathrm{mmol}$ ) was added dropwise to a stirred solution of 2-bromobiphenyl (1.00 g, $4.29 \mathrm{mmol})$ in dry THF $(3.0 \mathrm{ml})$ at $-78^{\circ} \mathrm{C}$ under a nitrogen atmosphere. After the addition was complete, the solution was warmed to room temperature over $30 \mathrm{~min}$. The mixture was cooled to $-78^{\circ} \mathrm{C}$ and a solution of 2 -adamantanone $(0.75 \mathrm{~g}, 5.0 \mathrm{mmol})$ in dry THF $(3 \mathrm{ml})$ was added dropwise. The solution was then warmed to room temperature and stirred overnight. The reaction contents were quenched with water and diluted with ethyl acetate. The organic phase was washed with water, dried over magnesium sulfate, evaporated, and recrystallized from a mixture of hexane and ethyl acetate to afford the alcohol $1(1.08 \mathrm{~g}, 82.6 \%) .{ }^{1} \mathrm{H}$ NMR $\left(\mathrm{CDCl}_{3}\right), \delta(\mathrm{ppm}): 1.43-1.86(\mathrm{~m}, 11 \mathrm{H}), 2.13(\mathrm{~d}, J=$ $12.3 \mathrm{~Hz}, 2 \mathrm{H}), 2.21(\mathrm{~s}, 1 \mathrm{H}), 7.09(\mathrm{dd}, J=7.7,1.5 \mathrm{~Hz}, 1 \mathrm{H})$, $7.23-7.36(\mathrm{~m}, 7 \mathrm{H}), 7.62(\mathrm{~d}, J=7.7 \mathrm{~Hz}, 1 \mathrm{H}) .{ }^{13} \mathrm{C} \mathrm{NMR}$ $\left(\mathrm{CDCl}_{3}\right), \delta$ (ppm): 26.7, 27.6, 33.2, 35.1, 35.4, 37.9, 78.1, 126.8, 127.0, 127.2, 127.5, 128.0, 129.3, 133.8, 142.1, 142.7, 145.2. HRMS $(\mathrm{m} / \mathrm{z}):\left[\mathrm{M}^{+}\right]$calcd. for $\mathrm{C}_{22} \mathrm{H}_{24} \mathrm{O}, 304.1827$; found, 304.1826.

\subsection{Spiro(adamantane-2,9'-fluorene) (2)}

A catalytic amount of $p$-toluenesulfonic acid was added to a solution of $1(1.00 \mathrm{~g}, 3.29 \mathrm{mmol})$ in acetic acid $(5.0 \mathrm{ml})$ and then the mixture was heated under reflux for $30 \mathrm{~min}$. The reaction mixture was poured into cold water and the precipitated was filtered and dried to give $2(0.91 \mathrm{~g}, 96.7 \%) .{ }^{1} \mathrm{H}$
NMR $\left(\mathrm{CDCl}_{3}\right), \delta(\mathrm{ppm}): 1.63(\mathrm{~s}, 2 \mathrm{H}), 1.81(\mathrm{~d}, J=13.5 \mathrm{~Hz}$, $4 \mathrm{H}), 2.01(\mathrm{~s}, 2 \mathrm{H}), 2.23(\mathrm{~s}, 2 \mathrm{H}), 2.96(\mathrm{~d}, J=12.9 \mathrm{~Hz}, 4 \mathrm{H})$, 7.31 (ddd, $J=7.7,7.2,1.4 \mathrm{~Hz}, 2 \mathrm{H}), 7.39$ (ddd, $J=7.7$, $7.2,1.2 \mathrm{~Hz}, 2 \mathrm{H}), 7.82(\mathrm{~d}, J=7.2 \mathrm{~Hz}, 2 \mathrm{H}), 8.13(\mathrm{~d}, J=$ $7.7 \mathrm{~Hz}, 2 \mathrm{H}) .{ }^{13} \mathrm{C}$ NMR $\left(\mathrm{CDCl}_{3}\right), \delta(\mathrm{ppm}): 27.7,34.6,35.2$, 41.8, 58.8, 119.7, 126.2, 127.1, 129.6, 141.1, 151.2. HRMS $(\mathrm{m} / \mathrm{z}):\left[\mathrm{M}^{+}\right]$calcd. for $\mathrm{C}_{22} \mathrm{H}_{22}, 286.1722$; found, 286.1717.

\subsection{Spiro[adamantane- $2,9^{\prime}-\left(2^{\prime}, 7^{\prime}\right.$-dibromofluorene $\left.)\right]$ (3)}

$\mathrm{FeCl}_{3}$ (catalytic amount) and bromine $(0.39 \mathrm{ml}, 7.50$ mmol) were added in the dark to a stirred solution of $\mathbf{2}$ $(1.00 \mathrm{~g}, 3.50 \mathrm{mmol})$ in chloroform $(20 \mathrm{ml})$ at $0{ }^{\circ} \mathrm{C}$. The solution was stirred at room temperature for $15 \mathrm{~h}$ and then poured into aqueous sodium thiosulfate solution and extracted with $\mathrm{CHCl}_{3}$. The organic layer was washed with water, dried over magnesium sulfate and evaporated. The residue was recrystallized from a mixture of hexane and $\mathrm{CH}_{2} \mathrm{Cl}_{2}$ to yield $3(1.40 \mathrm{~g}, 89.7 \%) .{ }^{1} \mathrm{H}$ NMR $\left(\mathrm{CDCl}_{3}\right), \delta$ (ppm): 1.59 (s, 2H), $1.80(\mathrm{~d}, J=13.8 \mathrm{~Hz}, 4 \mathrm{H}), 1.98(\mathrm{~s}, 2 \mathrm{H})$, $2.22(\mathrm{~s}, 2 \mathrm{H}), 2.80(\mathrm{~d}, J=12.9 \mathrm{~Hz}, 4 \mathrm{H}), 7.50(\mathrm{dd}, J=8.1$, $1.6 \mathrm{~Hz}, 2 \mathrm{H}), 7.60(\mathrm{~d}, J=8.1 \mathrm{~Hz}, 2 \mathrm{H}), 8.21(\mathrm{~d}, J=1.6 \mathrm{~Hz}$, 2H). ${ }^{13} \mathrm{C}$ NMR $\left(\mathrm{CDCl}_{3}\right), \delta$ (ppm): 27.3, 34.3, 34.9, 41.5, 59.4, 120.5, 120.8, 130.4, 132.6, 139.0, 152.8. HRMS $(\mathrm{m} / \mathrm{z})$ : $\left[M^{+}\right]$calcd. for $\mathrm{C}_{22} \mathrm{H}_{20}{ }^{81} \mathrm{Br}_{2}, 445.9891$; found, 445.9883; calcd. for $\mathrm{C}_{22} \mathrm{H}_{20}{ }^{79} \mathrm{Br}^{81} \mathrm{Br}$, 443.9911; found, 443.9893; calcd. for $\mathrm{C}_{22} \mathrm{H}_{24}{ }^{79} \mathrm{Br}_{2}$, 441.9931; found, 441.9907 .

\subsection{Preparation of Adm-TPD}

A mixture of compound $\mathbf{3}$ (800 mg, $1.80 \mathrm{mmol})$, $\mathrm{Pd}(\mathrm{OAc})_{2}(20.2 \mathrm{mg}, 90 \mu \mathrm{mol})$, and sodium tert-butoxide (415 mg, $4.32 \mathrm{mmol}$ ) was flushed with nitrogen several times. 3-Methyldiphenylamine $(0.62 \mathrm{ml}, 3.60 \mathrm{mmol})$, $\mathrm{P}(t-\mathrm{Bu})_{3}(0.5 \mathrm{M}$ in $o$-xylene, $0.72 \mathrm{ml}, 0.36 \mathrm{mmol})$, and dry $o$-xylene $(6.0 \mathrm{ml})$ were added sequentially into the flask under nitrogen. The reaction mixture was then heated at $120^{\circ} \mathrm{C}$ for $5 \mathrm{~h}$, cooled to room temperature, diluted with $\mathrm{H}_{2} \mathrm{O}$, and extracted with ethyl acetate. The combined organic solution was washed with brine, dried over $\mathrm{MgSO}_{4}$, evaporated, and purified by column chromatography using hexane/ethyl acetate $(100: 1)$ as the eluent to afford the amine Adm-TPD $(1.08 \mathrm{~g}, 92.5 \%) .{ }^{1} \mathrm{H}$ NMR $\left(\mathrm{CDCl}_{3}\right), \delta$ (ppm): $1.62-1.66(\mathrm{~m}, 6 \mathrm{H}), 1.86(\mathrm{~d}, J=19.4 \mathrm{~Hz}, 4 \mathrm{H}), 2.29$ (s, 6H), $2.57(\mathrm{~d}, J=12.7 \mathrm{~Hz}, 4 \mathrm{H}), 7.00-7.88(\mathrm{~m}, 24 \mathrm{H})$. ${ }^{13} \mathrm{C}$ NMR $\left(\mathrm{CDCl}_{3}\right), \delta(\mathrm{ppm}): 21.4,27.0,34.0,35.1,41.4$, 58.4, 118.2, 119.0, 119.5, 122.3, 122.6, 123.4, 124.2, 125.2, $125.5,126.0,129.0,138.9,145.2,151.9$. HRMS $(\mathrm{m} / \mathrm{z})$ : $\left[M^{+}\right]$calcd. for $\mathrm{C}_{48} \mathrm{H}_{44} \mathrm{~N}_{2}, 648.3505$; found, 648.3507 . Anal. calcd. for $\mathrm{C}_{48} \mathrm{H}_{44} \mathrm{~N}_{2}$ : C, 88.85; H, 6.83; N, 4.32. Found: C, 88.80; H, 6.95; N, 4.20.

\subsection{Preparation of Adm-NPD}

Adm-NPD was prepared (94.6\%) from compound 3 and $\mathrm{N}$-phenyl-1-naphthylamine following the procedure 


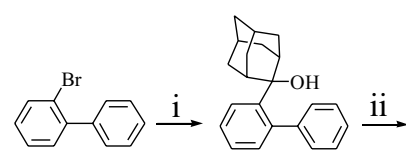

1

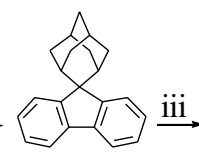

2

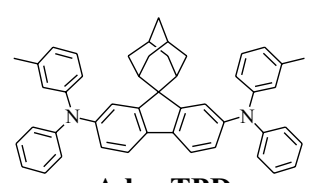

Adm-TPD
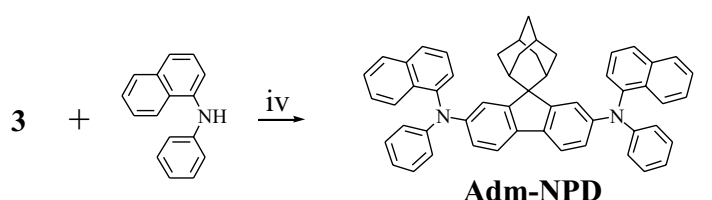

${ }^{\mathrm{a}}$ Reagents: (i) $n$-BuLi, THF, 2-adamantanone; (ii) $\mathrm{AcOH}, p$-TsOH (cat); (iii) $\mathrm{Br}_{2}, \mathrm{FeCl}_{3}$ (cat), $\mathrm{CHCl}_{3}$; (iv) $\mathrm{Pd}(\mathrm{OAc})_{2}$ (cat), $\mathrm{P}(t-\mathrm{Bu})_{3}, \mathrm{NaO}{ }^{t} \mathrm{Bu}, o$-xylene.

Scheme 1. Reagents: (i) $n$-BuLi, THF, 2-adamantanone; (ii) $\mathrm{AcOH}$, $p$ - $\mathrm{TsOH}$ (cat); (iii) $\mathrm{Br}_{2}, \mathrm{FeCl}_{3}$ (cat), $\mathrm{CHCl}_{3}$; (iv) $\mathrm{Pd}(\mathrm{OAc})_{2}$ (cat), $\mathrm{P}(t-\mathrm{Bu})_{3}$, $\mathrm{NaO}^{t} \mathrm{Bu}, o$-xylene.

described for the preparation of Adm-TPD. ${ }^{1} \mathrm{HNMR}$ $\left(\mathrm{CDCl}_{3}\right), \delta(\mathrm{ppm}): 1.47-1.52(\mathrm{~m}, 6 \mathrm{H}), 1.72(\mathrm{~d}, J=6.8 \mathrm{~Hz}$, $4 \mathrm{H}), 2.35(\mathrm{~d}, J=12.8 \mathrm{~Hz}, 4 \mathrm{H}), 6.94-7.24(\mathrm{~m}, 12 \mathrm{H})$, $7.34-7.52(\mathrm{~m}, 10 \mathrm{H}), 7.78(\mathrm{~d}, J=7.8 \mathrm{~Hz}, 4 \mathrm{H}), 7.91(\mathrm{~d}, J=$ $8.1 \mathrm{~Hz}, 2 \mathrm{H}), 8.04(\mathrm{~d}, J=8.4 \mathrm{~Hz}, 2 \mathrm{H}) .{ }^{13} \mathrm{CNMR}\left(\mathrm{CDCl}_{3}\right)$, $\delta$ (ppm): 27.1, 34.0, 35.1, 41.5, 58.2, 119.1, 121.3, 121.5, $124.2,124.5,126.2,12.4,126.5,127.3,128.5,129.2,135.4$, 145.8, 151.9. HRMS $(\mathrm{m} / \mathrm{z}):\left[M^{+}\right]$calcd. for $\mathrm{C}_{54} \mathrm{H}_{44} \mathrm{~N}_{2}$, 720.3505; found, 720.3502. Anal. calcd. for $\mathrm{C}_{54} \mathrm{H}_{44} \mathrm{~N}_{2}$ : C, 89.96; H, 6.15; N, 3.89. Found: C, 89.72; H, 6.31; N, 3.87.

\section{Results and discussion}

\subsection{Synthesis and characterization}

Scheme 1 shows the synthetic route to the spiro(adamantane-2, $9^{\prime}$-fluorene)-based triaryldiamines, Adm-TPD and Adm-NPD. Spiro(adamantane-2, $9^{\prime}$-fluorene) (2) was prepared by the reaction of 2-lithiobiphenyl with 2-adamantanone, followed by dehydrative ring closure of the result-

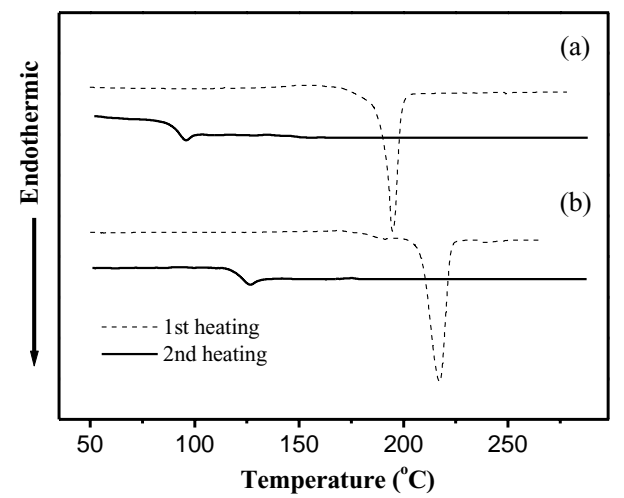

Fig. 1. DSC thermograms obtained upon sequential heating and cooling cycles of: (a) Adm-TPD and (b) Adm-NPD.

ing alcohol $\mathbf{1}$ in the presence of a catalytic amount of $p$-toluenesulfonic acid. Bromination of 2 with $\mathrm{Br}_{2}$ in the presence of $\mathrm{FeCl}_{3}$ resulted the dibromo compound $\mathbf{3}$. The $\mathrm{P}(t-\mathrm{Bu})_{3}$-palladium complex catalyzed the amination of 3 with diarylamines gave the target triaryldiamines, each containing a spiro(adamantane-2,9'-fluorene) core [32]. The chemical structures of Adm-TPD and Adm-NPD were confirmed by ${ }^{1} \mathrm{H}$ and ${ }^{13} \mathrm{C}$ NMR, high resolution mass spectrometry, and elemental analysis.

\subsection{Thermal properties}

The thermal properties of Adm-TPD and Adm-NPD were investigated by differential scanning calorimetry and thermogravimetric analysis; the results are presented in Table 1. Fig. 1 displays their DSC curves. DSC was performed in the temperature range between 30 and $300^{\circ} \mathrm{C}$. The polycrystalline samples of Adm-TPD and Adm-NPD that are obtained upon sublimation melt only on their first heating, at 195 and $217^{\circ} \mathrm{C}$, respectively, and then they change into a glassy state upon cooling from the melt. When these amorphous glassy samples are reheated, the former has a $T_{\mathrm{g}}$ at $94^{\circ} \mathrm{C}$, while the latter has a $T_{\mathrm{g}}$ at $125^{\circ} \mathrm{C}$; no exothermic peak resulting from crystallization is observed up to $300^{\circ} \mathrm{C}$. As shown in Table 1, the spiro(adamantane-2,9'-fluorene)-based triaryldiamines have higher values of $T_{\mathrm{g}}$ relative to their biphenyl analogs [25]. We attribute the increase in the

Table 1

Physical properties of triaryldiamines

\begin{tabular}{|c|c|c|c|c|c|c|}
\hline & $T_{\mathrm{g}}\left({ }^{\circ} \mathrm{C}\right)^{\mathrm{a}}$ & $T_{\mathrm{d}}\left({ }^{\circ} \mathrm{C}\right)^{\mathrm{b}}$ & $\lambda_{\max }(\mathrm{nm})^{\mathrm{c}}$ & $\lambda_{\mathrm{em}}(\mathrm{nm})^{\mathrm{c}}$ & $E_{1 / 2}^{\mathrm{ox}}\left(E_{\mathrm{onset}}^{\mathrm{ox}}\right)(\mathrm{mV})^{\mathrm{d}}$ & HOMO $(\mathrm{eV})$ \\
\hline Adm-TPD & 94 & 390 & 371 & 396 & $632,945(561)$ & 5.5 \\
\hline Adm-NPD & 125 & 430 & 352 & 465 & 651, $992(587)$ & 5.5 \\
\hline TPD & $60[25]$ & & 350 & 396 & 810,1059 (742) & 5.7 \\
\hline NPD & 95 [25] & & 336 & 448 & 845,1115 (771) & 5.7 \\
\hline
\end{tabular}

${ }^{a}$ Measured under nitrogen at a heating rate of $10{ }^{\circ} \mathrm{C} \mathrm{min}^{-1}$ and a cooling rate of $40^{\circ} \mathrm{C} \mathrm{min}^{-1}$.

${ }^{\mathrm{b}}$ The temperature corresponding to a $5 \%$ weight loss measured under nitrogen at a heating rate of $20^{\circ} \mathrm{C} \mathrm{min}^{-1}$.

${ }^{\mathrm{c}}$ Measured in EtOAc; the photoluminescence maximum was recorded upon irradiation at the absorption maximum.

${ }^{\mathrm{d}}$ Relative to a $\mathrm{Ag} / \mathrm{Ag}^{+}$reference. 
morphological stability of the fluorene-based materials to the presence of the rigid spiro-adamantane substituent at the central linkage, which may hinder the crystallization process $[29,30]$. It is important that OLEDs be constructed from materials having a relatively high value of $T_{\mathrm{g}}$ to avoid problems associated with grain boundaries in polycrystalline films [7-9]. Additionally, both Adm-TPD and Adm-NPD exhibit high thermochemical stability, as evidenced by thermogravimetric analysis, with $5 \%$ weight loss temperatures under nitrogen atmosphere of up to $390^{\circ} \mathrm{C}$.

To further investigate the morphological stability of Adm-NPD, we deposited a thin film on an indium tin oxide (ITO) substrate and measured its surface morphology by using atomic force microscopy (AFM) before and after annealing at $95^{\circ} \mathrm{C}$ for 3 days under a nitrogen atmosphere. For the sake of comparison, the same experiment was conducted with a film of NPD. As Fig. 2 indicates, the thin layer of Adm-NPD displays a fairly good surface morphology that is not changed upon annealing. In the case of the NPD film, the annealing induced a degradation of the surface morphology and, in addition, large crystals were observed on the annealed layer. It is apparent that the presence of the spiro(adamantane-fluorene) core inhibits the crystallization of Adm-NPD, which maintains its morphological stability in the glassy state.

\subsection{Optical properties}

The absorption and emission spectral data of the fluorene-based triaryldiamines are summarized in Table 1. In EtOAc solutions, Adm-TPD and Adm-NPD have lowest-energy transitions, with $\lambda_{\max }$ at 371 and $352 \mathrm{~nm}$, respectively, that we attribute largely to electron transfer from a nitrogen lone pair to the $\pi^{*}$ orbital of the biphenyl (fluorene) group [13]. The emission maxima are $396 \mathrm{~nm}$ for the former and $465 \mathrm{~nm}$ for the latter. The absorption bands of the fluorene-based triaryldiamines are significantly red-shifted $(16-21 \mathrm{~nm})$ with respect to those of their biphenyl analogs. This result indicates that the planar fluorenyl linkage plays an important role in enhancing the $\pi$ conjugation and reducing the HOMO-LUMO energy gap.

\subsection{Electrochemistry}

The electrochemical behavior of Adm-TPD and Adm-NPD was investigated by cyclic voltammetry using an $\mathrm{Ag} / \mathrm{Ag}^{+}$ reference electrode, as shown in Fig. 3, and the data are tabulated in Table 1. During the anodic scan, the triaryldiamines exhibit two reversible oxidations, each of which corresponds to the removal of one electron from a triarylamine group. Relative to their biphenyl analogs, the spiro(adamantane-fluorene)-based materials have lower (a)

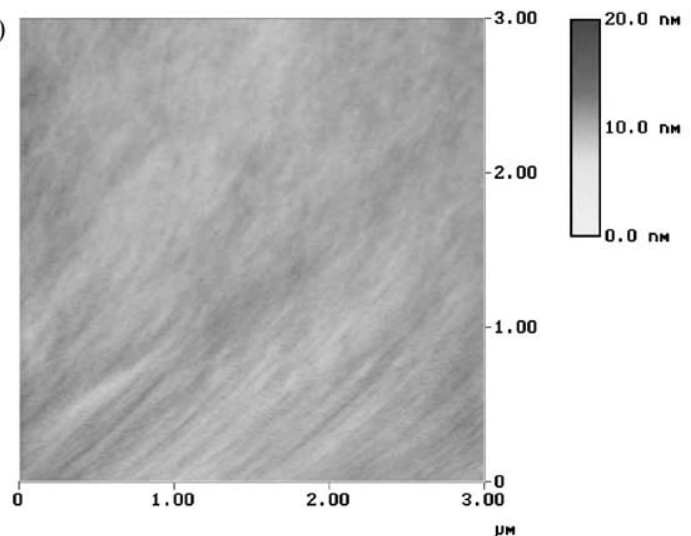

(b)

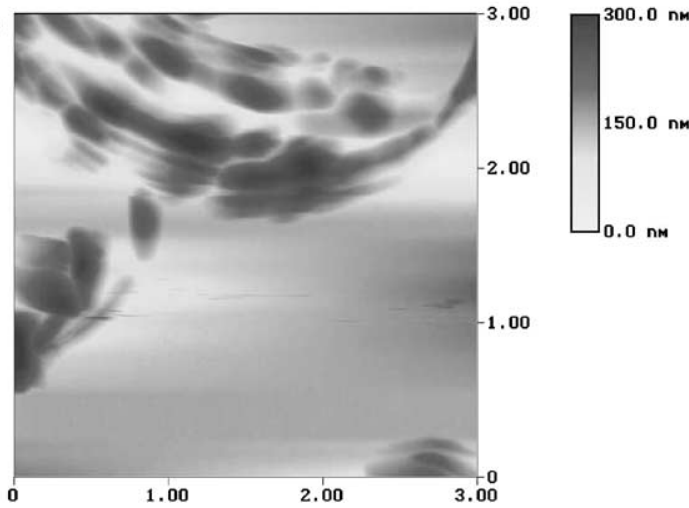

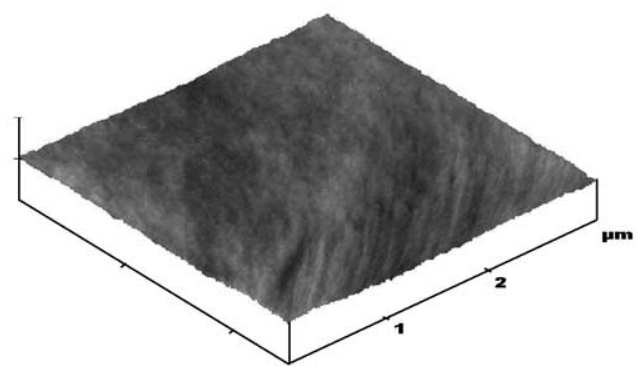

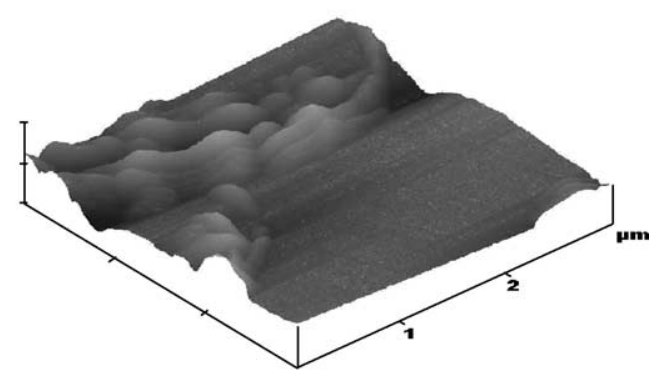

Fig. 2. AFM images (top and angled views) of: (a) an Adm-NPD layer and (b) an NPD layer, after annealing at $95^{\circ} \mathrm{C}$ for 3 days under a nitrogen atmosphere. 


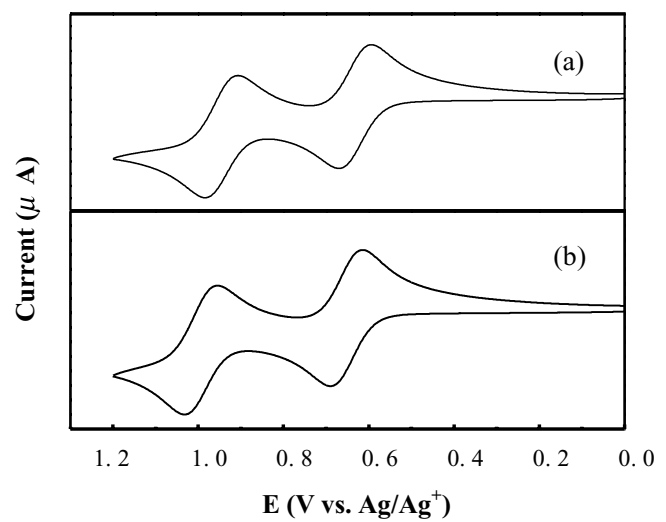

Fig. 3. Cyclic voltammograms of: (a) Adm-TPD and (b) Adm-NPD in $\mathrm{CH}_{2} \mathrm{Cl}_{2}$ containing $0.1 \mathrm{M} \mathrm{TBAPF}_{6}$.

oxidation potentials. This feature is due to the planarity of the fluorene core, which leads to better $\pi$ conjugation between the two amino groups [24]. Additionally, the larger potential difference between the first and the second oxidation steps in the fluorene-based triaryldiamines reveals that the radical cation that is formed is delocalized more efficiently by the fluorene-linkage than by the biphenyl one. Although the electrochemical data do not yield an exact value of the HOMO energy level, we observe trends that can be compared with the oxidation potentials of well-studied HTL materials with similar structures. The HOMO energy levels of Adm-TPD and Adm-NPD are calculated from the cyclic voltammetry studies to be 5.19 and $5.22 \mathrm{eV}$, respectively, when compared with the value obtained for NPD $(5.7 \mathrm{eV}$, estimated from the photoemission spectroscopy) [33].

\subsection{Electroluminescent devices}

To investigate the hole-transporting properties of the spiro-fluorene-based materials, Adm-NPD, which has the higher thermal stability of the two, was selected as the holetransporting layer in the fabrication of light-emitting diodes. Multilayer devices with the configuration ITO/Adm-NPD $(60 \mathrm{~nm}) / \mathrm{Alq}_{3}(75 \mathrm{~nm}) / \mathrm{LiF}(1.0 \mathrm{~nm}) / \mathrm{Al}(200 \mathrm{~nm})$ were fabricated by sequential vapor deposition of the materials onto a glass substrate coated with ITO. In this structure, the ITO and $\mathrm{Al}$ layers are the anode and cathode, respectively, $\mathrm{Alq}_{3}$ is used as both the electron-transporting layer and as the emitter, and $\mathrm{LiF}$ is the electron-injecting layer. A reference device composed of NPD/Alq 3 with the same thickness was also constructed for comparison.
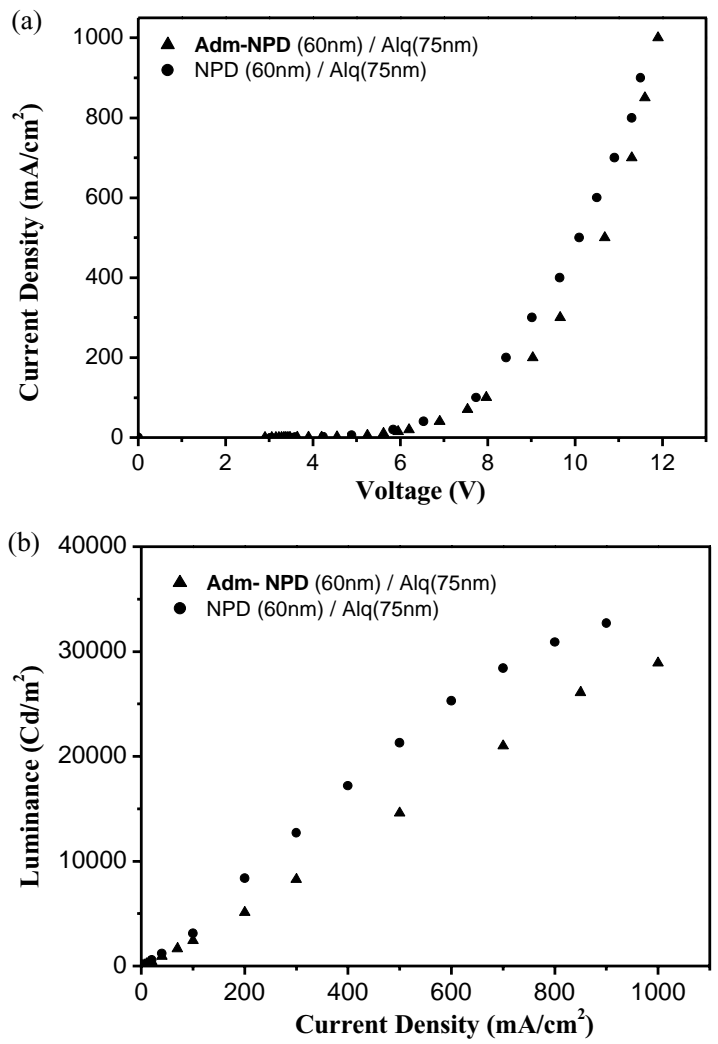

Fig. 4. (a) Current density-voltage characteristics and (b) luminescencecurrent density characteristics of Adm-NPD- and NPD-based OLEDs, having the configurations ITO/HTM $(60 \mathrm{~nm}) / \mathrm{Alq}_{3}(75 \mathrm{~nm}) / \mathrm{LiF}(10 \mathrm{~nm}) / \mathrm{Al}$ $(200 \mathrm{~nm})$

The current-voltage-luminance $(I-V-L)$ characteristics of the devices are shown in Fig. 4, and their performances are listed in Table 2. The OLED prepared with an Adm-NPD HTL has current-voltage characteristics very similar to the analogous NPD-based device. A bright green emission $\left(\lambda_{\max }=524 \mathrm{~nm}\right)$ from $\mathrm{Alq}_{3}$ was observed in both cases with turn-on voltages at ca. 3.3 V. The Adm-NPD-based device luminous efficiency achieves $2.44 \mathrm{~cd} \mathrm{~A}^{-1}$ (corresponding to a power efficiency of $0.96 \mathrm{~lm} \mathrm{~W}^{-1}$ ) at $100 \mathrm{~mA} \mathrm{~cm}^{-2}$ and exhibits a maximum luminescence of $28,900 \mathrm{~cd} \mathrm{~m}^{-2}$, which are values that are marginally lower than those of an NPD-based device. This outcome may be due to an inefficient carrier recombination in the Adm-NPD/Alq 3 device. The energies of the HOMOs of Adm-NPD, NPD, and $\mathrm{Alq}_{3}$ are 5.5, 5.7, and $6.0 \mathrm{eV}$, respectively. The greater energy offset between the HOMOs of Adm-NPD and $\mathrm{Alq}_{3}$ results in an increased barrier for migration of holes from

Table 2

EL performance of triaryldiamines ${ }^{\mathrm{a}}$

\begin{tabular}{llllll}
\hline & Driving voltage $(\mathrm{V})$ & $\begin{array}{l}\text { Current efficiency } \\
\left(\mathrm{cd} \mathrm{A}^{-1}\right)\end{array}$ & $\begin{array}{l}\text { Power efficiency } \\
\left(\mathrm{lm} \mathrm{W}^{-1}\right)\end{array}$ & $\begin{array}{l}\text { Maximum } \\
\text { luminance }\left(\mathrm{cd} \mathrm{m}^{-2}\right)\end{array}$ & $\begin{array}{l}\text { Peak wavelength } \\
(\mathrm{nm})\end{array}$ \\
\hline Adm-NPD & $6.12(7.97)$ & $2.21(2.44)$ & $1.14(0.96)$ & 28900 & 524 \\
NPD & $5.84(7.74)$ & $2.94(3.10)$ & $1.58(1.26)$ & 32700 & 524 \\
\hline
\end{tabular}

${ }^{a}$ Measured at a current density of $20 \mathrm{mAcm}^{-2}$. The data in the parentheses were taken at a current density of $100 \mathrm{~mA} \mathrm{~cm}^{-2}$. 
Adm-NPD to $\mathrm{Alq}_{3}$ and an inefficient recombination of holes and electrons in the $\mathrm{Alq}_{3}$ layer, relative to these process in $\mathrm{NPD} / \mathrm{Alq}_{3}[20,25]$.

In summary, we have synthesized new triaryldiamines, Adm-TPD and Adm-NPD, which each contain a spiro(adamantane-2,9'-fluorene) core. These compounds, which do not crystallize upon cooling from their melts or on heating above their values of $T_{\mathrm{g}}$, form amorphous films by vapor deposition. Relative to their known biphenyl analogs, the new fluorene derivatives possess higher glass transition temperatures and high HOMO energy levels, which we attribute to the presence of the rigid and planar spiro-fluorenyl core. AFM measurements reveal that the incorporation of the rigid spiro-core depresses the crystallization of Adm-NPD and allows it to maintain its morphological stability in the glassy state. A multilayer organic EL device using Adm-NPD as a hole-transporting layer-i.e., having the configuration ITO/Adm-NPD/Alq $3 / \mathrm{LiF} / \mathrm{Al}$ - produces a bright green emission with reasonably good EL performance. Further modification and optimization of the structure and device are in progress.

\section{Acknowledgements}

We thank the National Science Council of the Republic of China for financial support. We also thank Professor Chin H. Chen for assistance with the fabrication and measurement of OLED devices.

\section{References}

[1] C.W. Tang, S.A. Van Slyke, Appl. Phys. Lett. 51 (1987) 913.

[2] S. Miyata, H.S. Nalwa (Eds.), Organic Electroluminescent Materials and Devices, Gordon and Breach, New York, 1997.
[3] C.H. Chen, J. Shi, C.W. Tang, Macromol. Symp. 125 (1997) 1.

[4] C.H. Chen, J. Shi, C.W. Tang, Coord. Chem. Rev. 171 (1998) 161.

[5] U. Mitschke, P. Bauerle, J. Mater. Chem. 10 (2000) 1471.

[6] L.S. Hung, C.H. Chen, Mater. Sci. Eng. R 39 (2002) 143

[7] E. Han, L. Do, Y. Niiidome, M. Fujihira, Chem. Lett. (1994) 969.

[8] S. Tokito, Y. Taga, Appl. Phys. Lett. 66 (1995) 673.

[9] P.F. Smith, P. Gerroir, S. Xie, A.M. Hor, Z. Popovic, M.L. Hair, Langmuir 14 (1998) 5946.

[10] K. Naito, A. Miura, J. Phys. Chem. 97 (1993) 6240.

[11] S. Tokito, H. Tanaka, K. Noda, A. Okada, Y. Taga, Appl. Phys. Lett. 70 (1997) 1929.

[12] J. Salbeck, N. Yu, J. Bauer, F. Weissörtel, H. Bestgen, Synth. Met. 91 (1997) 209.

[13] B.E. Konne, D.E. Loy, M.E. Thompson, Chem. Mater. 10 (1998) 2235.

[14] D.F. O'Brien, P.E. Burrows, S.R. Forrest, B.E. Konne, D.E. Loy, M.E. Thompson, Adv. Mater. 10 (1998) 1108.

[15] F. Steuber, J. Staudigel, M. Stössel, J. Simmerer, A. Winnacker, H. Spreitzer, F. Weissörtel, J. Salbeck, Adv. Mater. 12 (2000) 130.

[16] Y.J. Shirota, Mater. Chem. 10 (2000) 1.

[17] P. Strohriegl, J.V. Grazulevicius, Adv. Mater. 14 (2002) 1439.

[18] M. Thelakkat, H. Schmidt, Adv. Mater. 10 (1998) 219.

[19] K. Katsuma, Y. Shirota, Adv. Mater. 10 (1998) 223.

[20] I.Y. Wu, J.T. Lin, Y.T. Tao, E. Balasubramaniam, Y.Z. Su, C.W. Ko, Chem. Mater. 13 (2001) 2626.

[21] C.W. Ko, T. Tao, Synth. Met. 126 (2002) 37.

[22] J. Salbeck, J. Bauer, F. Weissörtel, Macromol. Symp. 125 (1997) 121.

[23] M. Kimura, S.I. Inoue, K. Shimada, S. Tokito, K. Noda, Y. Taga, Y. Sawaki, Chem. Lett. (2000) 192.

[24] K.T. Wong, Z.J. Wang, Y.Y. Chien, C.L. Wang, Org. Lett. 3 (2001) 2285.

[25] D.E. Loy, B.E. Konne, M.E. Thompson, Adv. Funct. Mater. 12 (2002) 245.

[26] Y.-T. Chern, H.-C. Shiue, Macromolecules 30 (1997) 4646.

[27] S.-H. Hsiao, C.-T. Li, Macromolecules 31 (1998) 7213.

[28] Y.-T. Chern, H.-C. Shiue, Chem. Mater. 10 (1998) 210.

[29] S. Zheng, J. Shi, R. Mateu, Chem. Mater. 12 (2000) 1814.

[30] S. Wang, W.J. Oldham Jr., R.A. Hudack, G.C. Bazan, J. Am. Chem. Soc. 122 (2000) 5695.

[31] C.H. Chen, C.W. Tang, Appl. Phys. Lett. 79 (2001) 3711.

[32] T. Yamamoto, M. Nishiyama, Y. Koie, Tetrahedron Lett. 39 (1998) 2367.

[33] A. Rajagopal, C.I. Wu, A. Kahn, J. Appl. Phys. 83 (1998) 2649. 